\title{
Correction to: Methamphetamine Enhances HIV-Induced Aberrant Proliferation of Neural Progenitor Cells via the FOXO3-Mediated Mechanism
}

\author{
Minseon Park ${ }^{1}$ - William Baker ${ }^{1}$. Dilraj Cambow ${ }^{1}$ - Danielle Gogerty ${ }^{1}$ Ana Rachel Leda ${ }^{1}$. Bridget Herlihy ${ }^{1}$. \\ Darya Pavlenko ${ }^{1}$. Schuyler Van Den Nieuwenhuizen ${ }^{1} \cdot$ Michal Toborek $^{1,2}$
}

Published online: 6 October 2021

๑) Springer Science+Business Media, LLC, part of Springer Nature 2021

\section{Correction to: Molecular Neurobiology}

https://doi.org/10.1007/s12035-021-02407-9

The original version of this article unfortunately contained unconverted tagging in Introduction section that should be deleted.

The original article was corrected.

Publisher's note Springer Nature remains neutral with regard to jurisdictional claims in published maps and institutional affiliations.

The original article can be found online at https://doi.org/10.1007/ s12035-021-02407-9.

Minseon Park

mspark@med.miami.edu

$\triangle$ Michal Toborek

mtoborek@med.miami.edu

1 Department of Biochemistry and Molecular Biology,

University of Miami Miller School of Medicine, 1011 NW

15th Street, Miami, FL 33136, USA

2 Institute of Physiotherapy and Health Sciences, The Jerzy Kukuczka Academy of Physical Education, Katowice, Poland 